\title{
Prosthetic Valve Endocarditis
}

National Cancer Institute

\section{Source}

National Cancer Institute. Prosthetic Valve Endocarditis. NCI Thesaurus. Code C128356.

Endocarditis occurring on parts of a valve prosthesis or a reconstructed heart valve; it can be classified into early and late prosthetic valve endocarditis. 